\title{
Erratum zu: Methoden
}

\author{
Jörg Blasius
}

Online publiziert: 14. Juli 2021

(C) Der/die Autor(en) 2021

\section{Erratum zu:}

\section{Köln Z Soziol 2020}

https://doi.org/10.1007/s11577-020-00687-y

Der Artikel „Methoden“ von Jörg Blasius wurde ursprünglich Online First ohne „Open Access“ auf der Internetplattform des Verlags publiziert. Nach der Veröffentlichung in Bd. 72 Heft 2 pp. 305-308 hatte sich der Autor für eine „Open Access““Veröffentlichung entschieden. Das Urheberrecht des Artikels wurde deshalb in (C) Der/die Autor(en) 2021 geändert.

Funding Open Access funding enabled and organized by Projekt DEAL.

Open Access Dieser Artikel wird unter der Creative Commons Namensnennung 4.0 International Lizenz veröffentlicht, welche die Nutzung, Vervielfältigung, Bearbeitung, Verbreitung und Wiedergabe in jeglichem Medium und Format erlaubt, sofern Sie den/die ursprünglichen Autor(en) und die Quelle ordnungsgemäß nennen, einen Link zur Creative Commons Lizenz beifügen und angeben, ob Änderungen vorgenommen wurden.

Die in diesem Artikel enthaltenen Bilder und sonstiges Drittmaterial unterliegen ebenfalls der genannten Creative Commons Lizenz, sofern sich aus der Abbildungslegende nichts anderes ergibt. Sofern das betreffende Material nicht unter der genannten Creative Commons Lizenz steht und die betreffende Handlung nicht nach gesetzlichen Vorschriften erlaubt ist, ist für die oben aufgeführten Weiterverwendungen des Materials die Einwilligung des jeweiligen Rechteinhabers einzuholen.

Die Online-Version des Originalartikels ist unter https://doi.org/10.1007/s11577-020-00687-y zu finden.

Jörg Blasius $(\square)$

Institut für politische Wissenschaft und Soziologie, Universität Bonn

Lennéstr. 27, 53113 Bonn, Deutschland

E-Mail: jblasius@uni-bonn.de 
Weitere Details zur Lizenz entnehmen Sie bitte der Lizenzinformation auf http://creativecommons.org/ licenses/by/4.0/deed.de.

Jörg Blasius Prof. Dr., Professor am Institut für Politische Wissenschaft und Soziologie der Universität Bonn. Forschungsinteressen: Methoden der empirischen Sozialforschung, angewandte Statistik (insbesondere Korrespondenzanalyse), Stadtsoziologie, Lebensstile. Aktuelle Publikationen: Empirical Investigations of Social Space. Amsterdam 2019 (hrsg. mit F. Lebaron, B. Le Roux, A. Schmitz); Neighborhood Change. Results from a Dwelling Panell. In: Housing Studies 2019 (mit J. Friedrichs). 